\title{
Imágenes y voces de la ruralidad en clase de español
}

Diálogo entre literatura y producciones audiovisuales

\section{César Ruiz Pisano}

\section{OpenEdition}

\section{Journals}

Edición electrónica

URL: https://journals.openedition.org/cher/914

DOI: $10.4000 /$ cher. 914

ISSN: 2803-5992

\section{Editor}

Presses universitaires de Strasbourg

\section{Edición impresa}

Fecha de publicación: 12 diciembre 2019

Paginación: 101-115

ISBN: 979-10-344-0057-7

ISSN: 1968-035X

\section{Referencia electrónica}

César Ruiz Pisano, «Imágenes y voces de la ruralidad en clase de español», reCHERches [En línea], 23 | 2019, Publicado el 27 septiembre 2021, consultado el 17 noviembre 2021. URL: http:// journals.openedition.org/cher/914 ; DOI: https://doi.org/10.4000/cher.914 


\title{
Imágenes y voces de la ruralidad en clase de español Diálogo entre literatura y producciones audiovisuales
}

\author{
César Ruiz Pisano ${ }^{1}$
}

\begin{abstract}
Entre estos personajes, supervivientes de una civilización milenaria, aún se encuentran ejemplares de rara expresividad, filósofos rudimentarios y socarrones, dispuestos a exponer sus puntos de vista sobre la vida, los hombres y las cosas, tan pronto como su interlocutor se lo proponga ${ }^{2}$
\end{abstract}

\begin{abstract}
$\mathrm{L}$ a representación de lo rural en la ficción no puede considerarse como un elemento narrativo excepcional. Autores españoles como Delibes, Cela, Llamazares, Mateo Díez, o incluso tan recientes como Carrasco, han querido transponer en palabras un lugar y unos habitantes marcados, en su mayor parte, por unos rasgos comunes: la naturaleza, la adhesión a una cultura ancestral y una palabra habitualmente parca y a menudo indescifrable para el que le es ajeno. Lo mismo ocurre con la representación de lo rural en el cine o en la televisión ya sea mediante la adaptación de novelas o mediante la creación de nuevos mundos ficcionales ${ }^{3}$. Pensemos en Las Hurdes. Tierra sin pan (Buñuel 1933), Surcos (Nieves Conde 1951), Bienvenido Míster Marshall (García Berlanga 1953), Los Santos Inocentes (Camus 1984; adaptación de la obra de Delibes) y El Olivo (Bollaín 2016). Cabe decir, sin embargo, que el lenguaje audiovisual ha representado lo rural, las más de las veces y según los periodos, con una comicidad que cae fácilmente en lo ridículo, creando así estereotipos, como es la figura del paleto tanto en el cine como en la televisión ${ }^{4}$. No obstante, no se trata
\end{abstract}

1 César Ruiz Pisano, Université Paris 1 Panthéon-Sorbonne, ORCID: 0000-0003-39200723

2 Delibes, M., 2012, Castilla, lo castellano y los castellanos, Barcelona, Austral, p. 97.

3 Para una visión diacrónica se puede consultar: González Requena (1988), Ovies (2008), Gómez Gómez y Poyato Sánchez (2010), Monferrer (2015). La representación del mundo rural en la ficción televisiva es especialmente frecuente en la adaptación de obras literarias para Televisión Española.

4 Véase García de León (1993). 
de una visión divergente de aquella propuesta por la literatura sino que se trata, desde nuestro punto de vista, de una visión complementaria, incluso legítima, para aquellos que solo comprenden parcialmente las imágenes y las voces de lo rural.

La prueba de esto se encuentra en la variedad de documentos que proponemos para el análisis. Por ello, hemos querido mostrar lo rural a través de lenguajes distintos pero no excluyentes (el escrito y el audiovisual) y también a través de miradas igualmente distintas pero no excluyentes (del realismo existencialista a la parodia con tintes sentimentalistas). Al mismo tiempo, cabe precisar que, en la selección de los documentos, lo rural en la ficción nos traslada a épocas pasadas que representan un momento de la historia de la ruralidad española vista a través del tamiz del creador (escritor/director).

La unión de imágenes y de palabras sirve para dar cuenta de un universo ficcional que puede coincidir o no con la «resonancia personal» de cada lector/ espectador $^{5}$. Dicha excepcionalidad, que nace de las historias contadas, de las representaciones de un mundo distinto al nuestro y de una lengua igualmente extraña, nos sirve como elemento central en el trabajo con nuestros estudiantes. Así pues, hemos decidido introducir lo rural en clase de español abarcando la complejidad en su representación ficcional tanto por la forma como por el contenido, lo que, en cierta medida, hace de nuestra propuesta didáctica una excepción. Nuestros estudiantes inscritos en una clase específica de Cultura audiovisual (cuyo objetivo lingüístico es consolidar el nivel B2 e iniciar el C1 del Marco Común Europeo de la Lenguas) se adentran de esta forma en lo ruralficcional con el fin de reconocer su importancia cultural artística y lingüística. Se trata, en suma, de sensibilizar al estudiante sobre la excepción y lo excepcional del discurso rural.

Vamos a comenzar analizando la imagen, la representación que se da de lo rural, de la tierra y de sus gentes en las tres producciones para, luego, prestar atención a la voz rural, al uso de la palabra en el mundo rural ficcional. Terminaremos proponiendo una unidad didáctica tal y como la hemos concebido para nuestras clases de español.

\section{La imagen de lo rural}

Mostrar lo rural cuando el lector y el telespectador, en nuestro contexto educativo, se encuentran tan alejados en su representación mental y físicamente de ese mundo solo parece un precipicio franqueable gracias a la ficción. Esto supone sellar un pacto ficcional mediante el cual el observador acepte que se le lleve de la mano al descubrimiento de personajes y lugares que rompen esquemas porque son ajenos a su realidad inmediata.

5 Igartua Perosanz (2007: 52-53). 


\section{Acacias 38}

Y, para empezar ${ }^{6}$, los esquemas se rompen al pasear por la calle Acacias de la telenovela de TVE (Acacias $38^{7}$ ). Al hacerlo, se rompen los límites del tiempo, ya que la serie nos traslada al cambio del siglo xIX al xx, y también los límites del espacio esperado, porque el decorado es el de un barrio burgués (e idealizado) de una ciudad provinciana donde conviven aristócratas, burgueses y sus sirvientes. De esta forma, el espacio rural en la serie muta, sustituyendo la tierra por los adoquines, pero sin desaparecer del todo ${ }^{8}$. En efecto, en el altillo del número 38, donde se encuentran las habitaciones de los criados, se recrea entre alacenas, mesas camilla y cazuelas de barro un ambiente sencillo, afable y ajeno a las tensiones de convivencia que se viven en los elegantes pisos burgueses. Allí viven las mujeres representantes de un mundo rural desarraigado que abandonaron sus aldeas con la intención de medrar en la ciudad. Sus mejores representantes son las jóvenes Lolita y Casilda, pues ambas recuerdan las bondades de sus pueblos natales, sus paisajes, su folclore y sus gentes, inscribiéndose así en la tradición de la alabanza de aldea. Ambas son el prototipo de personaje rural, de «buen salvaje», y responden así a los estereotipos del imaginario español sobre las sirvientas: gente buena (bonachona incluso), bruta (ajena a exquisiteces y superficialidades de etiqueta), sincera (aunque no corresponda) y sencilla (cayendo en la simpleza). Ambas se asemejan, especialmente en el uso de la lengua, aunque esto no quiere decir que sean personajes clónicos representantes de una masa rural uniforme emigrada a la ciudad. Así, Lolita, originaria del pueblo imaginario de Cabrahigo, es el prototipo de moza resultona, graciosa, colérica y extrovertida. Por su parte, Casilda es el prototipo de la moza introvertida, 'tontita' y afable.

De esta forma, tal y como afirmaron los creadores de la serie ${ }^{9}$, se recrea el ambiente y se caracteriza a los personajes siguiendo, y transformando, el modelo de la literatura realista del siglo XIX y la inspiración reside especialmente en los personajes de Fortunata y Jacinta (Pérez Galdós 1899) ${ }^{10}$. Así, en la serie, tras un proceso de neutralización de caracteres, los habitantes de las corralas madrileñas han pasado al altillo conservando el gracejo popular y un regusto rural que aflora con facilidad.

6 La presentación y análisis de los documentos se realiza teniendo en cuenta las épocas representadas en la ficción (de la más alejada a la más reciente).

7 Acacias 38 lleva en antena desde abril de 2015 y en 2019 superará los 1000 episodios. De libre acceso en línea: <http://www.rtve.es/alacarta/videos/acacias-38/>.

8 Son escasas las secuencias rodadas en exteriores y las que representan explícitamente lo rural nos trasladan a lugares inhóspitos, aislados y que incitan al crimen.

9 Ver: <http://www.rtve.es/television/acacias-38/la-serie/>.

10 Ruiz Pisano y Dubois (2018). 


\section{La ciudad no es para mí}

En la película La ciudad no es para mí (Lazaga 1965'11), adaptación de la obra literaria escrita por el académico F. Lázaro Carreter, la oposición ruralidad/ urbanismo encuentra a su mejor representante en el protagonista, Agustín Valverde, quien deja su pueblo aragonés, Calacierva (pueblo ficcional), para ir a visitar a su hijo a Madrid ${ }^{12}$. Agustín es el prototipo de hombre rural, apegado a su tierra y a su gente e incapaz de adaptarse a la modernidad de la urbe y al cambio de costumbres en las relaciones personales. Esta comedia es un producto de la España del desarrollismo que encuentra en su protagonista, el actor Paco Martínez Soria, uno de sus mejores iconos.

Lo rural, en la línea de otras películas comerciales de los años 1960 y 197013, aparece representado como el edén de quienes no pueden adaptarse a una sociedad en plena mutación mientras que la ciudad, epicentro de la modernidad, acoge a otro tipo de inadaptados: aquellos que han suplantado la bondad y el amor familiar por el consumismo a ultranza y las modas urbanitas ${ }^{14}$. Entre ambos mundos se encuentra Filo (Gracita Morales), cuyo papel de criada la sitúa ya instalada en la ciudad pero cuyas maneras todavía guardan la campechanía de la vida en el pueblo. De hecho, ella viene a ser un equivalente de Lolita y Casilda de Acacias 38, pues hace la alabanza de la aldea en detrimento de la urbe:

Si es que en casa no me puedo reír porque la señora me echa la bronca. Yo aquí poco voy a aguantar, siempre con este cuello que parece que asoma una por una chimenea. Cada día me acuerdo más de mi pueblo. Allí se ríe y se llora y se canta y se baila y hasta se puede una mojar los pies en el río (La ciudad..., 00.45')

En la película, la figura rural de Agustín es doblemente importante porque, por un lado, representa en su pueblo la generosidad hacia sus convecinos, a quienes ayuda económicamente con su propio dinero y, cuando se le acaba, sonsacando dinero a su propio hijo. Esta bondad corresponde perfectamente a la imagen de una ruralidad pacífica, portadora de valores y promotora del respeto hacia la autoridad moral de los mayores. De ahí que se anhele su vuelta al pueblo como si de un hijo pródigo se tratara. Por otro lado, Agustín se convierte en elemento moralizador de los ciudadanos que han olvidado los valores fundamentales de la familia, el respeto y la humildad. De esta forma acepta una misión que nadie le pidió, que es la de encarrilar a cada miembro de su familia: hacer que su hijo se ocupe más de su esposa e hija, que su nuera no reniegue de

11 En línea: <https://gloria.tv/video/kxGe8xevPjCA3RGM44K6LxtbZ>. «¿Una dictadura liberal? (1962-1969)» de Casimiro Torreiro (en R. Gubern et al. 2010) permite comprender el contexto histórico y cinematográfico de los años 60. Huerta Soriano y Pérez Morán (2012) muestran los vectores temáticos (tradición y modernidad), narrativos (el patriara benefactor) y estéticos (costumbrismo y estilo didáctico) de las películas del «ciclo Paco Martínez Soria».

12 J. Peris Llorca (2007) hace un análisis descriptivo de la película.

13 El turismo es un gran invento (P. Lazaga, 1968), Abuelo made in Spain (P. Lazaga, 1969) o Vente a Alemania, Pepe (P. Lazaga, 1971).

14 «Esto no es el pueblo, nosotros vivimos de otra manera» le dicen a Agustín. 
sus orígenes rurales, que su nieta sepa aprender a divertirse en su justa medida e, incluso, que la criada encauce su vida tras un embarazo inesperado. Sin embargo, lo que hace que esta película sea una comedia y no un drama moralizador es que Agustín anda sobre ‘terreno asfaltado' para el que no está preparado, lo que da lugar a múltiples situaciones cómicas que muestran su inadaptabilidad al espacio urbano y, como veremos, esto también pasa por el uso de la lengua.

El regreso al pueblo, que no se da sin comicidad, supone la vuelta a lo existencial. Ante la pregunta de qué hará a partir de ahora en el pueblo, Agustín responde: "Lo que hace to'l mundo: estar pendiente de si llueve o nieva, si la cosecha va a ser buena o mala, si en aquella casa nace uno y si en la otra se va otro pa'rriba, ¿qué vas a hacer?» (La ciudad..., 01.28’)15.

\section{El disputado voto del señor Cayo}

En El disputado voto del señor Cayo, novela de Delibes $\left(1978^{16}\right)$, el espacio rural sirve de ambientación a la historia contada. En este caso, los inadaptados son los políticos urbanitas, quienes descubren asombrados el universo rural del protagonista. Así pues, lo que debía tratarse de un viaje propagandístico en aquella campaña electoral del año 1978 se convierte en una especie de descubrimiento de un mundo ancestral olvidado. Así, el viaje al pueblo aislado del señor Cayo se convierte en un viaje iniciático cuando los forasteros se encuentran con un saber ancestral (obviado u olvidado) y con un existencialismo molesto (porque pone en entredicho su propia visión de la existencia).

De esta forma, lo rural, que tanto asombro produce en los visitantes (regocijando parsimoniosamente al señor Cayo), se recrea en los espacios (la casa nobiliaria, la ermita románica, la cueva y su cascada, el huerto, la sala de la casa), en las acciones del anciano (mostrar su entorno, recoger la miel) y en el discurso del mismo, como veremos más adelante. Sin embargo, el descubrimiento por parte de los visitantes es progresivo, ya que exige atención y supone también el superar ciertos escollos como aceptar lo extraño y darse cuenta de su propia ignorancia. Los visitantes no están, pues, preparados para ver, oír y, sobre todo, entender un mundo que les es ajeno y que les provoca impotencia y malestar, ya que se dan cuenta de la imposibilidad de hacer dialogar existencias tan dispares, aunque estuvieron muy cerca de poder lograrlo.

Por todo ello, el señor Cayo no es un prototipo, es la esencia misma de lo rural $^{17}$. Reúne en sí mismo el saber ancestral, el apego a la tierra y el respeto de los seres vivos, la aceptación de los designios divinos y la inadaptación a una

15 Formulación similar a la del señor Cayo: «-¿Pensar? Y ¿qué quiere usted que piense? -Qué se yo, en el huerto, en las abejas... ¡Algo! El señor Cayo se pasó su mano grande, áspera, por la frente. Dijo: - Si es caso, de uvas a brevas, que si me da un mal me muero aquí como un perro» (Delibes, El disputado voto del señor Cayo, p. 118).

161978 [2010], Barcelona: Austral.

17 Talavera Muñoz (2010: 218): «El señor Cayo no sólo aparece envuelto en un ambiente rural, sino que es una pieza más de dicho contexto, un elemento necesario que contribuye a crear dicho espacio pero que, al mismo tiempo, nace de él [...]». 
modernidad que, porque le excluyó o porque se olvidó de él, ya no le concierne. La visión de lo rural, en esta obra, no es cómica, aunque por momentos haga sonreír, ni es trágica, aunque por momentos sea brutal. Esta visión existencialista lleva al lector a preguntarse qué tiene el señor Cayo que yo no tengo y que hace de él un ser excepcional.

\section{La lengua de lo rural}

La representación de lo rural se vería incompleta y en gran medida traicionada si no se diera también a nivel lingüístico. Por supuesto, pese a la aspiración al realismo, queda claro que el estado de lengua mostrado es aquel que corresponde a la ficción.

\section{Acacias 38}

En Acacias 38, la excepcionalidad del español de finales del siglo XIX se da en dos niveles ${ }^{18}$. Por un lado, a nivel de las unidades fraseológicas, un rasgo que no desarrollaremos aquí19. Por eso, en los diferentes capítulos de la serie que analizamos se acumulan refranes, proverbios y otras expresiones lexicalizadas de tal manera que mostrar el español de la época implica, por falta de otros recursos léxicos y por falta de un corpus oral sincrónico que sirviese de modelo, que la autenticidad pase por ello. Por otro lado, la representación de lo rural en un ambiente urbano burgués gracias, especialmente, a las intervenciones de las habitantes del altillo proporciona ejemplos suficientes sobre la recreación de un español rural, aunque difícilmente identificable con un dialecto geográfico. Lolita y Casilda representan un habla rural llena de vulgarismos, de pronunciaciones marcadas por la síncopa de consonantes, de sufijos diminutivos y de prefijos reiterativos. Esta habla sirve para identificar a los personajes con su clase social, como lo manifiestan Lolita: "Y ya sé que él es refinao y un señoritingo con estudios, listo y bien hablao. Que hasta pronuncia todas las eses. Y yo criada, bruta y mal hablada hasta decir basta» (Cap. 570) o Jacinto, recién llegado del pueblo: "Quiero aprender a hablar con los humanos» (Cap. 621).

Desde el punto de vista fonético, la pronunciación de los personajes del altillo, y especialmente de Lolita y de Casilda, aun siendo diferente ${ }^{20}$, está marcada por una apertura o cierre del timbre vocálico acompañada por una elisión o un añadido de consonantes, apócope de sílabas, metátesis vocálica o silábica y una abundancia de prefijación y de sufijación apreciativa.

18 Ruiz Pisano y Dubois (2018).

19 Véase particularmente Ruiz Pisano (2019).

20 Podemos reconocer una pronunciación con un cierre vocálico más importante en Casilda que en Lolita. Aun así, es difícil identificar el verdadero origen de su habla dialectal. Algunos rasgos podrían asimilarse fácilmente al diasistema aragonés mientras que otros al castellano (Castilla-La Mancha). Al escuchar hablar a las actrices fuera de escena nos damos cuenta de que se trata efectivamente de una recreación de un sociolecto rural. 
He aquí algunos ejemplos que muestran la riqueza del habla popular y rural de los personajes: endeluego, naide, epitrafio, ande, cuala/cualo, aluego, asín, rechiflar, requetebonico, rediez, una miajilla, mismico, mu malamente, pa qué, na, uséase, abandoná, inyicciones, ignoranta, encanturreao ${ }^{21}$.

\section{La ciudad no es para mí}

Por su parte, el entrañable Agustín recrea el ruralismo aragonés. De hecho, Paco M. Soria es originario de Tarazona y su habla aragonesa es una de las características de la mayoría de los personajes que ha representado en el cine. La recreación humorística del habla rural aragonesa del personaje principal de la película ha sido objeto de estudio por parte de M. Porroche Ballesteros (2004) a partir de la obra de teatro radiofónica que dio origen a la adaptación cinematográfica. Entre los rasgos más destacados, la autora cita, por ejemplo, a partir del análisis de una transcripción de 58 líneas, la abundancia de sonidos paralingüísticos ( $e h, n e$ ), índices de modalidad (quita, meca, je je), la pérdida de consonantes y de vocales ( $p a$, tos, pallá, usté, colorao, amos), la inestabilidad vocálica (cerculación, hiciendo), la colocación de pronombres átonos en posición proclítica (me se iba), el artículo ante un nombre propio (el Rufino) o la abundancia del sufijo diminutivo mayoritario del habla aragonesa (solico, vueltecicas). Efectivamente, estos rasgos caracterizan el habla del personaje de la película ( ¿Quién es este hombre tan rural?» dice una marquesa al oírle hablar) y aparecen reforzados por las intervenciones de otros personajes que toman la palabra en el pueblo de Calacierva: míe usted, malacatones, recibicos, me se olvidaba, un cogotazo, pa que no me s'apolille, no sé ni ande está, denque, tenís (por tenéis), ya empecemos (por empezamos), la calumnia (por la columna), tas casau, un retulo, murtoria, etc.

Además, el contraste campo/ciudad aparece reforzado por la jerga juvenil yeyé que, por ejemplo, acumula extranjerismos como en esta escena cómica $(0.46 ')$ :

Agustín: ¿Este mozo es tu novio?

Gogo: ¡Eh, frene! Que yo estoy en retaguardia... [...] Yo soy Gogo.

Agustín: ¿Y eso es el apellido $u$ qué santo es?

Gogo: [...] Oye, ¿sabes que me cae muy bien tu abuelo? Nos lo tenemos que llevar al club o a sierra [...] Te pierdes un desmelenao bárbaro, iba a presentarte a cinco gorilas al estilo Marlon... ¡A A ! Y Cholo lleva su rulot, ¡menudo camping!

NiETA: ¡De camping nothing!

$21 \mathrm{Y}$, en particular, en los fragmentos estudiados: 1. endeluego, sacao, pa que no se marchite, marcho (uso no pronominal vulgar del verbo «marcharse» en el oeste peninsular), na, en de que llegó de Cabrahigo, soy una nanai y menos, pa lo que sea menester, fenestaciones (por «defenestración»). Y las expresiones: entregar la pelleja, estar pasando las de Caín, entregar a la parca, ser más lista que el hambre. 2. Berríos, rediez, quia, na ni nadie, po, mu bien. 
Gogo: Lo malo será que el déspota no quiera soltar el carro.

Agustín: ¿Pero van en carro?

Nieta: ¡No abuelo, el carro es el automóvil!

Gogo: Claro, y el déspota, el padre. Oye, ipero hay que explicárselo todo!

\section{El disputado voto del señor Cayo}

Si bien se han escrito estudios sobre la lengua de Delibes en los que se presta una especial atención al riquísimo léxico que fluye por las páginas de sus novelas, vamos a presentar en estas líneas los rasgos representativos que nos servirán después para la construcción de la unidad didáctica ${ }^{22}$. Por un lado, tal y como ya afirmó M. Alvar (1983: 311-313), llama la atención en esta obra la oposición del «lenguaje ciudadano, zafio, tosco, paupérrimo» de los "politiquillos de tres al cuarto» y el lenguaje "rural, exacto, matizado, riquísimo» del señor Cayo. Aunque M. Alvar subraya que «lo que ese lenguaje representa es incultura, pobreza mental, negación del pensamiento», quizás de lo que se trate sea de un habla diferente («Hablamos dos lenguas distintas», Delibes (1978: 149)), aquella de los jóvenes de los años 80 , un habla canalla que se amolda bien al rupturismo de una época marcada por los cambios políticos y sociales. Su habla no es ni mejor ni peor que la del señor Cayo sino diferente, al igual que la de Gogo respecto a la de Agustín. Así lo demuestra el siguiente ejemplo:

-A esta azada hay que mangarla

-Mangar, ¿es poner mango?

-Natural

_En la ciudad, mangar es robar (El disputado...// Delibes 1978: 86)

El español «canalla» de los visitantes se caracteriza por la rapidez de las réplicas y por un léxico innovador y, cierto es, muchas veces, cargado de palabras malsonantes ${ }^{23}$. He aquí algunos ejemplos del libro: enrollarse, comer el coco, dar el coñazo, ser pera en dulce, ser un macarra, fardarlfardón, cantidad (de mola cantidad), el rollo, macho, estar out, jo, quedón, tío/tía, demasié, tócame el haba, etc. Y muchos joder y coño.

En cambio, el habla del señor Cayo es parca y, al mismo tiempo, a ojos del forastero/lector, extremadamente rica porque le es desconocida al ser dialectal y conservadora (M. Alvar habla de «la voz de la tierra») ${ }^{24}$. Esta habla corresponde

22 Véase, en lo que concierne a El disputado voto..., A. Flores Ramírez (2002); M.J. Talavera Muñoz (2010).

23 Como escribió F. Rodríguez González (1987: 65): «Se produjo el nacimiento de una jerga juvenil, lo que se ha dado en llamar cheli, pasota o lenguaje del rollo, que alcanzó a finales de la década una enorme difusión [y que dejarían] de formar parte de una jerga incomprensible para convertirse en muletillas inevitables en cualquier conversación».

24 «-Yo veo una cosa aleteando en el cielo y sé que es un pájaro. Veo una cosa verde agarrada a la tierra y sé que es un árbol, pero no me preguntéis sus nombres - bajó la cabeza de golpe y ocultó el rostro entre las manos-: Yo no sé una puñetera palabra de nada» dice uno de los visitantes (Delibes 1978: 134). 
con la idea del mundo rural que quiere transmitir Delibes, la visión de un mundo aislado, que desaparece al tiempo que desaparecen sus habitantes, quienes saben nombrarlo ${ }^{25}$. Acceder a la sabiduría ancestral del señor Cayo no es un ejercicio fácil porque el que llega desconoce ese mundo y sus componentes, de ahí que, como halo de esperanza, se da un proceso de aprendizaje intensivo que le anonada («es increíble») y que invierte la identificación del «paleto». Por eso las preguntas de los forasteros se acumulan: «¿Un enterizo?», «¿Qué planta es ésta?», "iJoder -dijo, ¿se comían ustedes las lombrices?», «¿Por qué es pájaro de mala ralea el cuclillo?». Por ello, ¿quién es ahora el ignorante, el paleto?

En oposición a los personajes de ficción hasta ahora evocados, el señor Cayo habla poco, y su habla poco tiene que ver con la acumulación de ruralismos/ vulgarismos de Agustín o de Casilda. Notamos, sin embargo, la presencia de índices de modalidad presentes en el habla rural, como interjecciones, quia o toó, así como otros modalizadores, natural, qué hacer, cuya función es la de corroborar o contradecir una información (equivalentes de pues claro o para nada según el caso). La tendencia a esa parquedad lingüística favorece la presencia de respuestas unívocas, lacónicas (eso, natural, "Aquí, ella; es muda»), otras breves, sentenciosas y cargadas de sabiduría: «La abeja posa donde posa la reina», «Todas detrás, es la regla», «Los dujos son, a ver, las colmenas», «El cárabo es ${ }^{26}$ », «El palo con su raíz, solo, no sujeta», "No hay peor curia que la de la misma manera». La voluntad de Delibes es la de traducir en palabras la vida y el mundo rural del señor Cayo donde lo superfluo no tiene cabida.

\section{Una propuesta didáctica}

Esta propuesta didáctica, puesta en práctica con estudiantes no especialistas matriculados en estudios de Historia, Filosofía, Historia del Arte y de Cine, se integra en la materia Cultura audiovisual del mundo hispánico (nivel B2 hacia $\mathrm{C} 1$, clases de $1 \mathrm{~h} 30$ ) en la que nos hemos propuesto estudiar las relaciones texto escrito-texto (audio)visual desde una perspectiva cultural y crítica $^{27}$. Así, gracias a esta unidad titulada "Voces e imágenes de lo rural», los estudiantes realizan un análisis de algunas de las representaciones de lo rural (ámbito, personajes y habla) en la ficción española a partir de una variedad de formatos: pintura, cine, serie televisiva y literatura. Por ello, siguiendo nuestra investigación sobre el desarrollo de la destreza de comprensión audiovisual, prestamos especial atención al poder semiótico de la imagen ${ }^{28}$.

25 Es lo que demuestra en su estudio Fernández Martínez (2017).

26 Se observa el desplazamiento del verbo al final de la frase.

27 Para dar otros ejemplos de unidades: «La creación y el análisis» (donde se introduce el concepto de intermedialidad), "Cómo contar una época» (sobre la representación de las convenciones sociales), «La locura de amor» (sobre la representación del amor sin límites), «Lorca: del verso a la imagen», etc.

28 Ruiz Pisano (2016). 
He aquí la ficha de la unidad:

\begin{tabular}{|l|l|}
\hline $\begin{array}{l}\text { Voces e imágenes de lo rural } \\
\text { Público universitario }\end{array}$ Nivel B2 $>$ C1 & $\begin{array}{c}\text { Doc. 1: Campesinos (J.M. Díaz Caneja, 1950, pintura) } \\
\text { Doc. 2: «Castilla» (M. de Unamuno, 1907, poesía) } \\
\text { Doc. 3: El disputado voto del señor Cayo (M. Delibes, } \\
\text { 1978, Cap. V, novela) }\end{array}$ \\
& $\begin{array}{r}\text { Doc. 4: El disputado voto del señor Cayo (A. Giménez- } \\
\text { Rico, 1986, película) } \\
\text { Doc. 5: La ciudad no es para mí (P. Lazaga, 1966, } \\
\text { película + cartel). }\end{array}$ \\
& Doc. 6: Acacias38 (Boomerang TV/TVE, 2015-, serie TV)
\end{tabular}

Objetivos culturales: Representaciones de la vida rural en la ficción, artistas españoles del siglo xx, la ficción comercial de los años del desarrollismo, dualidad campo/ciudad. Objetivos lingüísticos específicos: Sensibilizar a los rasgos más recurrentes del habla rural: léxico, entonación y morfosintaxis (síncopa, sufijación, índices de modalidad).

Destrezas: Ser capaz de entender una gran variedad de textos complejos dentro de su campo de especialización (humanidades). Saber expresarse de manera fluida, espontánea y bien organizada para fines sociales y académicos.

\section{Descubrir el paisaje rural (castellano)}

Abrimos la unidad con un diálogo entre la pintura y la poesía, y con ello asociamos lo visual/textual con una experiencia sensorial que rompe con la imagen que los estudiantes pueden tener del espacio rural. Para alcanzar este objetivo proponemos el estudio del cuadro titulado Campesinos (1950), del artista palentino Díaz Caneja ${ }^{29}$, en el que el espacio rural se aleja de una visión de lo natural tradicional (vegetación preferiblemente verde y abundante, animales, casas tradicionales, etc.). Este cuadro de constante cubista se caracteriza por un método que «[...] consiste en la geometrización cristalina de toda la superficie del cuadro, construyéndolos a modo de tela de araña donde quedan atrapados los cerros, el horizonte, la luz y el cielo castellano» ${ }^{30}$. El paisaje castellano aparece hecho de líneas con una paleta de colores que van del amarillo al gris, pasando por una gran variedad de ocres, lo que dificulta la identificación del campo, las casas y los personajes. Pensamos que la voluntad del autor es mostrar la infinitud de un campo seco, durante la época de la siega, lo que se refuerza con la perspectiva del horizonte visto desde el páramo.

Esta visión peculiar del campo dialoga con la que nos ofrece Miguel de Unamuno con el poema Castilla ${ }^{31}$, en el que la voz poética hace un canto de alabanza de la tierra castellana. El poema transmite lo perceptible (la rugosidad y la aspereza de la tierra, sus colores, la desnudez del campo, la infinitud del

29 En la página web de la fundación encontramos una descripción de su trayectoria pictórica así como el cuadro Campesinos (pintura central de la tercera línea de cuadros expuestos). En línea: <http://www.diaz-caneja.org/content/obra>, fecha de consulta: $10 / 01 / 19$.

30 En línea: <http://www.diaz-caneja.org/content/obra>, fecha de consulta: 10/01/19.

31 Poesías (1907), <https://www.poemas-del-alma.com/castilla.htm>. 
horizonte) y el yo poético alcanza la plenitud entre llanura y páramo, de cuya admiración surge la inspiración.

Así, pintura y poesía permiten establecer relaciones sensoriales que insisten en una visión admirativa del campo castellano de forma que las imágenes y las palabras se hacen eco al tiempo que sorprenden al estudiante que pueda carecer de este tipo de referentes naturales.

El acceso al contenido de los documentos se facilita mediante un contexto didáctico que contiene léxico y pistas de análisis que guían la explicación conjunta de los documentos. El trabajo se puede realizar de forma individual o colectiva. Para la clase siguiente presentan otro cuadro (libre elección) de Díaz Caneja para relacionarlo con lo estudiado.

\section{Contar el mundo rural}

Tras la presentación del mundo rural mediante la imagen y la voz poética, estudiamos un fragmento de la obra analizada de Delibes (cap. V, fragmentos de las p. 67-80) y que corresponde a la llegada de los tres políticos al pueblo del señor Cayo. Esta parte de la obra nos interesa porque, junto a los visitantes, nos adentramos en un pueblo que impresiona por su arquitectura noble, igual que impresionaban los paisajes antes vistos. También impresiona la soledad («Esto está completamente abandonado»). La riqueza del léxico utilizado para describir al personaje y el lugar, lo mismo que la precisión de las parcas palabras del señor Cayo, demuestra que allí reside el saber ancestral. Por ello, los estudiantes van a poder justificar lo que diferencia a los forasteros y al oriundo: las continuas preguntas, las exclamaciones y los exabruptos del que no sabe y las respuestas sabias, casi proverbiales, del que sabe. Además, lo diferente también adquiere la forma de marcadores como esos toó o quia. Igualmente, se presta atención a la intervención de la mujer del señor Cayo, quien, siendo muda, se comunica con sonidos guturales, animalización que caracteriza a ciertos personajes rurales en la obra de Delibes ${ }^{32}$.

Para completar esto, se visualiza, para la siguiente clase, un fragmento de la adaptación hecha por Giménez-Rico en 1986, especialmente las escenas que transcurren dentro de la casa del señor Cayo, pues refuerzan la idea de incomprensión entre los dos mundos y se manifiesta el aislamiento del campesino, quien tan solo cree en los elementos naturales y en la ineluctable muerte $^{33}$. El fragmento termina con un «alucinante» dicho por el forastero ${ }^{34}$.

32 Por ejemplo, los personajes de Las Ratas (1962) o de Los Santos Inocentes (1981) de los que se pueden extraer fragmentos para ejemplificar mejor la lengua rural de Delibes.

33 Ver: <https://www.youtube.com/watch?v=VAaudNjr_Rc $>$ y $<$ https://www.youtube. com/watch?v=MgAAD2npra0 $>$.

34 Ver Pérez Millán (2013) sobre la representación de la oposición campo/ciudad en las adaptaciones cinematográficas de las obras de Delibes. 
Así pues, las preguntas formuladas a los estudiantes buscan la caracterización de los personajes de forma que el medio rural, el aspecto físico y las palabras utilizadas sirvan para mostrar la oposición entre el forastero y el campesino. El texto y las imágenes son compatibles y permiten completar esta caracterización. Además, la frase de la voz narrativa «Bajo el añoso roble, la voz calmosa del señor Cayo, cobraba un noble acento profesoral» da pie a una reflexión sobre la naturaleza del saber que reside en el campo y aquel que quiere imponerse desde la ciudad, ya que los forasteros insisten en la ausencia de radio, televisión y la falta de contacto con la realidad exterior.

\section{Las dos caras del «paleto»}

La polaridad de los dos mundos se pone de manifiesto en la película $\mathrm{La}$ ciudad no es para mí, que, en clave cómica, completa la caracterización en la ficción del hombre rural, quien esta vez se adentra en el terreno ajeno. Por ello, comenzamos con el análisis del cartel de la película, ya que permite hacer un vínculo descriptivo con la representación física del señor Cayo, así como el campesino del cuadro de Díaz Caneja. Su físico se convierte así en el estereotipo del hombre rural.

Es necesario, para comprender esta diferencia, contextualizar la situación socioeconómica de aquella España de los años 1950 y 1960: el Plan de Estabilización, la visita de Eisenhower, la emigración del campo a la ciudad, etc. Optamos, además, por relacionar este contexto con lo cinematográfico, viendo un tráiler amateur de la película Bienvenido Míster Marshall (García Berlanga 1953) para que los estudiantes capten la comicidad al tiempo que observan el comienzo de la evolución de la sociedad franquista ${ }^{35}$.

El estudio de los primeros minutos de la película de Lazaga nos da las claves para ver la gran diferencia de ambientes entre los dos mundos: el urbano es estrepitoso y artificial mientras que el rural es tranquilo y natural. Ambos están llenos de vida pero esta se muestra de maneras diametralmente opuestas. Sigue el visionado del fragmento en el que se narra la llegada de Agustín a la ciudad y a la casa de su hijo (0.18'-0.30'), lo que nos lleva a la caracterización del «paleto» mediante su aspecto y sus acciones, así como su habla excepcional. Se presta especial atención a la entonación, los vulgarismos, la sufijación. Para reforzar el análisis comparativo mediante el habla, visualizamos la escena del encuentro entre Agustín, su nieta y Gogo donde se manifiesta la jerga juvenil yeyé $(0.46$ '). Además, para observar el uso contemporáneo de algunos de los rasgos lingüísticos que caracterizan el habla de Agustín, los estudiantes realizan búsquedas en el Coser (Corpus Oral y Sonoro del Español Rural), que ofrece una gran variedad de ejemplos orales con su transcripción como para la sufijación apreciativa, la secuencia de clíticos (me se) y adverbios (Fernández-Ordóñez 2015). Se trata de observar los rasgos sacados de la ficción en un contexto real de uso contemporáneo.

35 Ver: $<$ https://www.youtube.com/watch?v=5rJ7YDQZfos $>$. 


\section{El habla rural: ¿un habla atemporal?}

Para consolidar lo estudiado hasta el momento damos un salto en el tiempo gracias a la serie Acacias 38 para mostrar cómo el fenómeno de la emigración del hombre rural a la ciudad no es algo nuevo. Los ejemplos de Lolita y de Casilda permiten entonces completar la caracterización del personaje rural de la ficción $\mathrm{y}$, especialmente, el personaje femenino como prolongación de Filo, que figura en La ciudad no es para mí. Tras la contextualización de la trama narrativa de la serie, se visualizan dos fragmentos que muestran, respetando los códigos de la telenovela, cómo se constituyen las relaciones de clase y cómo se expresan estos personajes ${ }^{36}$. En el primer fragmento se presencia la conversación entre Casilda y Lolita y luego cómo Antoñito, joven burgués enamorado de Lolita, intenta encontrar en Casilda una celestina para facilitar ese amor. En el segundo fragmento, asistimos, con el paso del tiempo, al acto desesperado de Lolita por declarar su amor delante de todo el vecindario a su enamorado Antoñito. A partir de estos fragmentos, los estudiantes caracterizan a los personajes, su origen, su medio social, la situación tragicómica y cómo se adapta la serie al género de la telenovela. Además, a nivel lingüístico pueden reconocer rasgos estudiados (especialmente la síncopa, prefijación/sufijación y algunos vulgarismos) e insistir en el gusto por la exageración como recurso cómico (comparaciones, lexicalización y exclamaciones varias). Conviene igualmente constatar su uso en el Coser y en el Diccionario de la Lengua Española.

Por último, se cierra la unidad con una reflexión personal del estudiante sobre lo que significan «las voces y las imágenes de la ruralidad española en la ficción». Para completar esta reflexión los estudiantes disponen de un nuevo fragmento sacado de Las ratas (Delibes 1962) y otro de la película El turismo es un gran invento (Lazaga 1968), que refuerzan la visión dual de la ruralidad que han podido descubrir en la unidad a través de la imagen y de la lengua.

\section{Conclusión}

A lo largo de este artículo hemos intentado analizar la representación del ambiente y del habla rural en la televisión, el cine y la literatura. Hemos insistido en el análisis de los documentos en la dualidad campo/ciudad como motor narrativo y como fuente de diferenciación lingüística. Tal como se ha podido constatar, aunque el prototipo de lo rural otorga unidad a la selección propuesta, la caracterización de cada personaje se da de tal manera que estos se convierten en representantes excepcionales de un mundo que sorprende al lector/telespectador. Por ello, nos ha parecido necesaria una transmisión de este saber rural a nuestro alumnado tal y como lo hemos reflejado en la construcción de una unidad donde la reflexión sobre el ambiente y las voces de lo rural se dan

36 Ver: <https://www.youtube.com/watch?v=jXjsj_qPaSs> y <https://www.youtube. $\mathrm{com} /$ watch? $\mathrm{v}=\mathrm{BNiEaGD} 4 \mathrm{SBc}>$. 
gracias a una variedad de formas artísticas que abundan en la riqueza narrativa y lingüística de lo que podemos considerar, a primera vista, excepcional.

\section{Bibliografía}

Acacias 38, 2015-, Boomerang TV Producciones, <http://www.rtve.es/alacarta/ videos/acacias-38/>.

Alvar M., 1983, «Lengua y habla en las novelas de Miguel Delibes», Bulletin Hispanique, 85-3-4, p. 299-323.

Delibes M., 1962 [2001], Las ratas, Barcelona, Austral.

Delibes M., 1978 [2010], El disputado voto del señor Cayo, Barcelona, Austral.

Díaz-Caneja J. M., Fundación Díaz Caneja, Palencia, <http://www.diaz-caneja. org/>.

Fernández-Ordóñez I. (coord.), 2015, Corpus Oral y Sonoro del Español Rural (COSER), <http://www.corpusrural.es/index.php >.

Fernández Martínez P., 2017, «Por los caminos venatorios de Miguel Delibes: palabras para un paisaje», Lengua y Habla, 21, p. 175-201.

Flores Ramírez A., 2002, "Registros lingüísticos e intención comunicativa en El disputado voto del señor Cayo de Miguel Delibes", in Echenique M.T. y Sánchez Méndez J.P., Actas del V Congreso Internacional de Historia de la Lengua Española, p. 1171-1190.

García de León M. A., 1993, «Los personajes rurales en el cine español: (Historia y sociología de un arquetipo rural: la figura del paleto)», in Actas del IV Congreso de la A.E.H.C., Madrid, Editorial Complutense, p. 321-332.

Giménez-Rico, A. (1986), El disputado voto del señor Cayo, España [DVD, Filmax Pictures].

Gómez Gómez A. y Poyato Sánchez P., 2010, Profundidad de campo: más de un siglo de cine rural en España, Gerona, Luces de Gálibo.

González Requena J., 1988, «Apuntes para una historia de lo rural en el cine español», in El campo en el cine español, Madrid, Filmoteca Española, p. 13-27.

Gubern R., Monteverde J.E., Pérez Perucha J., Riambau E. y Torreiro C., 2010, Historia del cine español, Madrid, Cátedra.

Huerta Soriano M.A. y Pérez Morán E., 2012, «La creación de discurso ideológico en el cine popular del tardofranquismo (1966-1975): el 'ciclo Paco Martínez Soria'», Comunicación y Sociedad, Vol. 25, 1, p. 289-311.

Igartua Perosanz J.J., 2007, Persuasión Narrativa, Alicante, Editorial Club Universitario.

Lazaga, P. (dir.), 1966, La ciudad no es para mí, España [DVD, Tribanda Pictures]. Monferrer A., 2015, "Nuevas y viejas ruralidades. Reflexiones sobre la representación cinematográfica de la ruralidad española», Rassegna iberistica, vol. 38, 104, p. 255-273, <https://edizionicafoscari.unive.it/en/edizioni/riviste/ rassegna-iberistica/2015/104/nuevas-y-viejas-ruralidades/>. 
Ovies A., 2008, «Campo y ciudad en el cine español», I Congreso Internacional de Historia y Cine (2007), Universidad Carlos III de Madrid. Instituto de Cultura y Tecnología, p. 798-809, <http://e-archivo.uc3m.es/handle/10016/17803>.

Pérez Millán J., 2013, "Campo y ciudad en el cine basado en la obra de Miguel Delibes", in Celma Valero P. y Rodríguez Sánchez De León M.J. (coord.), Miguel Delibes: nuevas lecturas críticas de su obra, Ediciones de la Universidad de Salamanca, p. 139-144.

Peris Llorca J., 2007, «Si “La ciudad no es para mí”, ¿podría decirme dónde queda el campo?: una lectura de la película de Pedro Lazaga (1965)», Actas del I Congreso Internacional de Lengua, Literatura y Cultura Española (Valencia), p. 363-375, <https://dialnet.unirioja.es/servlet/articulo?codigo=2341095>.

Porroche Ballesteros M., 2004, «Estudio de una elaboración humorística del español hablado en Aragón", in Enguita Utrilla J. M. (coord.), Jornadas sobre la variación lingüística en Aragón a través de los textos, p. 205-226.

Rodríguez González J., 1987, «El lenguaje pasota, espejo de una generación», Revista de Estudios de Juventud, junio, p. 65-71.

Ruiz Pisano C. (2019, en prensa), «L'espagnol du XIX ${ }^{\mathrm{e}}$ siècle 'vu' à la télévision: étude phraséologique de la série Acacias 38», Epilogos, Université de Rouen, $<$ https://webtv.univ-rouen.fr/videos/13-03-2018-163659/>.

Ruiz Pisano C., 2016, Théorie et pratiques de la compréhension audiovisuelle dans l'enseignement de l'espagnol langue étrangère, Tesis (dir. J. Vicente Lozano), Universidad de Ruan.

Ruiz Pisano C. y Dubois G., 2018, «Ambiguïté sociolectale et diatopique dans une série télévisée contemporaine: de l'analyse à une pratique éducative», Les Cahiers Linguatek: L'ambiguïté, 3-4, p. 259-272.

Talavera Muñoz M. J., 2010, «La lengua popular del señor Cayo como reflejo de la realidad y sus variedades lingüísticas en Miguel Delibes», in Cañas Murillo J., Grande Quejigo F.J. y Roso Díaz J. (eds.) Literatura popular e identidad cultural: estudios sobre folclore, literatura y cultura populares en el Mundo Occidental, Universidad de Extremadura, p. 215-220. 